\title{
The Use of Computed Tomography to Analyse Grinding Smudges and Subsurface Defects in Roller Bearing Rings
}

\author{
Andrzej Zbrowski* - Krzysztof Matecki \\ National Research Institute, Institute for Sustainable Technologies, Poland
}

This article shows that changes occurring on the surface of roller bearings in the form of grinding smudges stem from the subsurface material defects of these elements. The authors discuss how the smudges are created and show the results of computed tomography tests conducted for roller bearing rings with the above-mentioned defects. The ring reconstruction images are presented, and the defects are located and described with the use of reverse engineering. The defects identified are presented in radiographs. The topography tests confirmed the existence of subsurface defects that emerge on the surface in the form of smudges, once the grinding of an element starts.

Keywords: roller bearing rings, material defects, non-destructive tests, computed tomography

\section{INTRODUCTION}

Defects in roller bearing rings stem from incorrectly conducted technological processes, e.g. metallurgical processes, forging, thermo-mechanical processing, or machining. Each such mistake made can be the cause of a different kind of defect. The most dangerous are internal material defects as cracks, micro-shrinkage, overlapping, etc., which appear just under the surface. The high load in the defect area results in excessive stress travelling deep below the surface. As a result, there is a sudden and unexpected damage to the roller bearing, shortening the expected time of its operation. Detection of these defects during the manufacturing process is possible only when they appear on the surface of the element and become visible to the naked eye, or can be spotted using specialised defectoscopy instrumentation dedicated to mass production systems. The defects usually "make themselves visible" during the final stage of processing, i.e. during the grinding of the surface of the element. The incorrect parameters of this final process cause surface defects in the form of different surface hardnesses, tension, micro-cracks, grinding burns and smudges. While the first of them are the results of thermal loads, the smudges can result from the "open (exposed)" subsurface defect, which cannot be observed with the naked eye. The defect can be confirmed only when the element is subjected to defectoscopy tests by means of computed tomography [1] to [3].

The tests were intended to prove that there is a direct connection between the inner material defects and the occurrence of grinding smudges on the surface of the element studied.

The purpose of the test was to detect defects in the internal structure of the ring under the ground surface on which the smudges were formed. The authors used computed tomography methods to look for defects including voids, blisters, cracks, and porosity, which can be found during the grinding process.

\section{APPLICATION OF COMPUTED TOMOGRAPHY FOR NON-INVASIVE TESTS}

The X-ray computed tomography (CT) is commonly used in industrial non-destructive tests for technical objects [4] and [5]. Based on the X-rays in different sections, spherical images are generated, which are then used for dimensional analyses, and constitute an important element of reverse engineering. CT enables material defectoscopy tests in which cracks, discontinuity, inclusions, or structural defects are detected. The fundamental advantage of the CT method is the possibility of conducting non-contact, spatial analysis of the internal structure of the tested element with a resolution of up to $1 \mu \mathrm{m}$ [6]. The precision of the method is so high that it enables the determination of the spatial arrangement of crystallites of the tested material [7]. Therefore, the CT method was used for the observation of the microstructure and the propagation of the defect in a model composite material in elements manufactured using the sintering method [8] and [9]. In order to determine the influence of the material deformation on the internal structure of the foamed metal using the CT method, an analysis of the structure of these metals was conducted [10] and [11], followed by an analysis of the foamed polypropylene [12] and [13]. The results obtained enabled the experimental verification of the computer simulation of the deformation.

Due to its high resolution, the CT method was used for the inspection of the quality of the metal foaming process [14]. The examination of the microstructure of the walls of inner cells of the foamed metals was also conducted; as a result, blisters were detected [15]. In the case of structure deformation tests, the CT 
method enables the recording of the sintering process [16]. The observation of the microstructure of the sintered material, in turn, allowed the experimental verification of computer simulations.

The CT method is common in tests on the internal structure of metal elements [17], as well as in the study of the microstructure of the casts of non-ferrous metals [18].

The tomography tests were used to determine the Young modulus of metal-ceramic composites [19]. Based on the spatial model, a computer simulation was carried out for the deformation of the sample. The Young modulus, determined using computer simulation, was then compared to the results of experimental tests.

The CT method allows the spatial mapping of the structure of metallic and non-metallic materials [20]. The use of the CT method also enables the determination of the distribution of the density of the sintered metal [21], which in turn allows the simulation of geological processes [22] and/or the simulation of the impact of the pile foundation on the ground [23].

\section{CREATION OF GRINDING SMUDGES}

The grinding is the final stage of surface generation. It has an influence on the accuracy of the shape, size, and smoothness of working surfaces and the condition of the surface layer. The grinding process affects the utility properties of the roller bearings and the safety of their operation. During the grinding process, certain subsurface defects concerning the inner structure of the element may become visible. Any detected defect automatically discredits an element and necessitates its exclusion from further manufacturing processes.

Visible symptoms of the existence of inner defects in the structure of the investigated material are surface smudges stemming from the grinding process (Fig. 1).

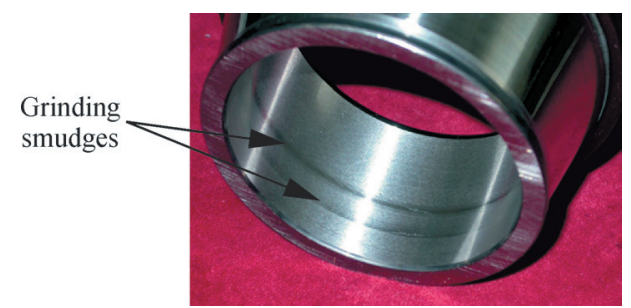

Fig. 1. Grinding smudges on the inner ring of the roller bearing

A smudge is created on the surface using a grinding wheel.
During the grinding of the inner rings of tapered roller bearings, grinding wheels with $508 \mathrm{~mm}$ in diameter, 7 to $40 \mathrm{~mm}$ in width, hardness $\mathrm{J}$ and $\mathrm{K}$, and structure 8 are used. The abrasive used in them is alumina or sintered alumina with a grain size of 140 $\mu \mathrm{m}$. The cutting speed is $60 \mathrm{~m} / \mathrm{s}$. During grinding, the wheel encounters discontinuities located just under the surface of the material ground.

Such material defects resulting from the rolling, forging or casting processes are usually filled with impurities from metallurgical or forging processes. The grinding wheel opens up the material discontinuities, extracts the impurities, and smudges them over the ground surface, which creates smudges of different colours and lustre. The size of the smudge depends on the kind, shape, and location of the discontinuity. The greater the size of the discontinuity, the wider and clearer the smudge. Even when the opening in the discontinuity of the material is small, the smudge can be visible to the naked eye, not to mention specialised optical inspection systems. A roller bearing ring with the detected defect in form of a grinding smudge should be excluded from any further manufacturing process.

\section{TEST STAND}

The rings were tested using the Phoenix $\mathrm{v} \mid$ tome $\mid \mathrm{x}$ s240 X-ray computed scanner, which enabled the projection of objects from different directions and helped to obtain the reconstruction images of the layered roller bearing rings, which in turn facilitated the spatial imaging of the defects under the surface of the tested objects. A CT device is an automatic device employing VGStudio MAX 2.1 software. The data are collected and processed using Phoenix datos/x 2 acq software, but for the reconstruction, Phoenix datos/x $2 \mathrm{rec}$ is used. The time of reconstruction is approximately $30 \mathrm{~min}$ for a resolution of $\sim 80 \mu \mathrm{m}$.

Table 1. Scanner setting parameters

\begin{tabular}{lc}
\hline Parameter & Value \\
\hline Accelerating voltage & $210 \mathrm{kV}$ \\
\hline Current & $210 \mu \mathrm{A}$ \\
\hline Voxel size & $\approx 98.5 \mu \mathrm{m}$ \\
\hline Number of images & 1600 \\
\hline Exposure time & $200 \mathrm{~ms}$ \\
\hline Radiation filter & $0.2 \mathrm{~mm} \mathrm{Cu}$ \\
\hline
\end{tabular}

The steel that the rings are made of is characterised by high density, which significantly 
reduces the possibility of transmittance, which makes it difficult to obtain a desired X-ray contrast and the reconstruction image. Some of the defects, particularly the small ones, can be unclear, and their imaging with the use of reconstruction images requires proper accuracy of tests, which depends, inter alia, on the number of projections. The scanner setting parameters are presented in Table 1.

The detection of internal defects is also possible when magnetic, ultrasonic methods and eddy current methods are applied. Computed tomography, however, is the only method providing a quantitative and qualitative assessment of the ring structure and enabling the three-dimensional visualization of the defect.

\section{TEST OBJECT}

The $\mathrm{A}$ and $\mathrm{B}$ roller bearing rings with visible grinding smudges made of the $100 \mathrm{Cr} 6$ steel were tested (Fig. 2). The hardness of the surface after the heat treatment was 58 to $62 \mathrm{HRC}$.

Fig. 3.

The geometry of the test object is presented in

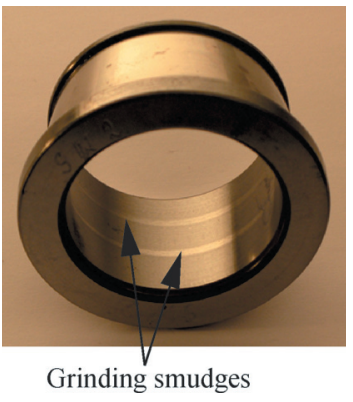

a)

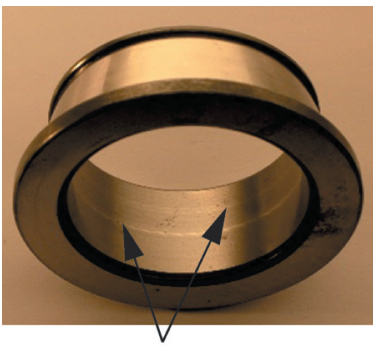

Grinding smudges

b)
Fig. 2. Test objects for rings: a) $A$ and b) $B$

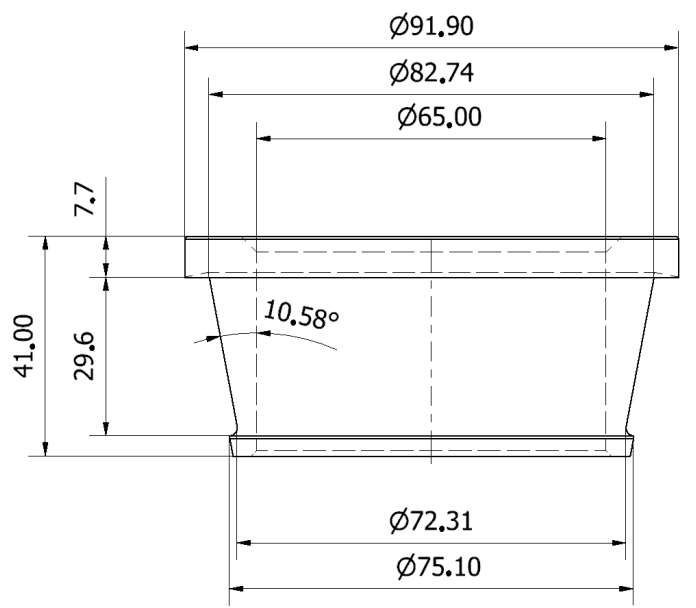

Fig. 3. Geometry of the test object; dimensions in $\mathrm{mm}$

\section{TEST RESULTS}

3D images were obtained for both $\mathrm{A}$ and $\mathrm{B}$ rings. A method of computed tomography was used (Fig. 4) to detect the location of the defect (marked with numbers 1 and 2).

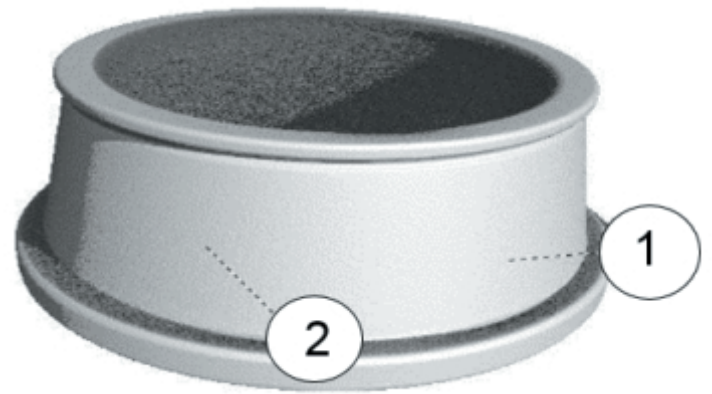

a)

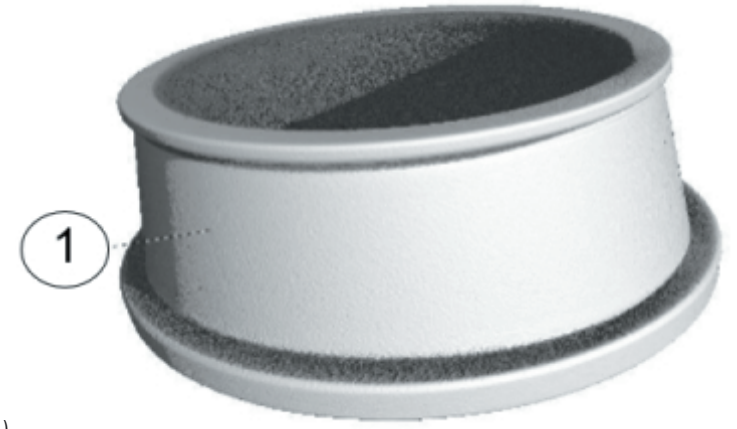

Fig. 4. Tomography reconstruction image for rings a) Ring $A$ and $b$ ) Ring $B$

In the case of Ring $\mathrm{A}$, two discontinuities were detected; whereas only one defect was detected in the case of the other ring. In order to enable a more detailed description of the defects, three perpendicular sections of the reconstructed objects were created. They allowed the determination of the character, orientation and the topography of the discontinuity. The examples of the images of Defect 1 in Ring A in the defined axes are depicted in Fig. 5.

In order to make the images of the defect more readable, the geometry of the object was reconstructed (Fig. 6). The imaging of the geometry of the defect was conducted using the results of the measurements taken for the reconstructed 3D model.

Discontinuity 1 in Ring A is similar to the crack or the flattened cavity with extended topography in the direction perpendicular to the inner surface of the ring (Fig. 6).

The examples of the images of the area in which Defect 2 was observed for Ring A are shown in Fig. 7. 


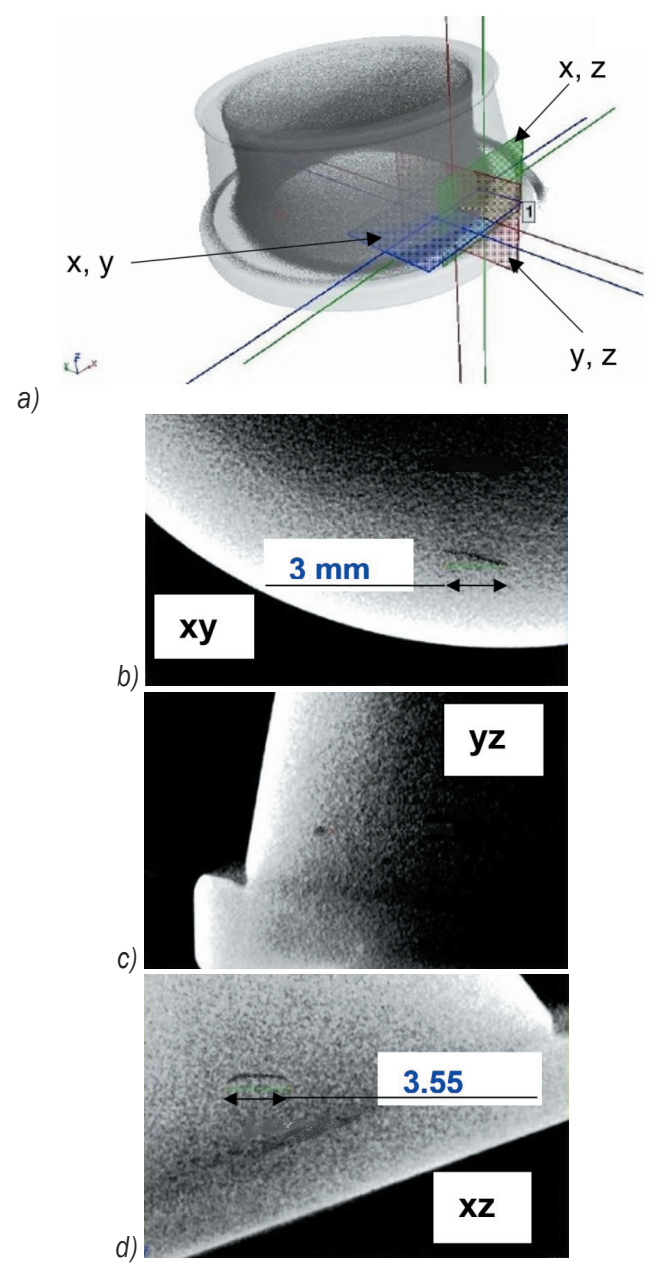

Fig. 5. Selected images of sections in xyz axes of Defect 1 in the reconstruction of a) ring $A, b) x y$ intersection, c) $y z$ intersection, $d$ ) $x z$ intersection

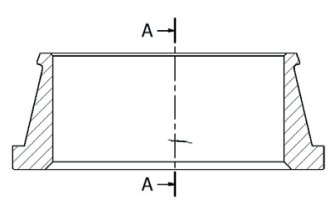

a)

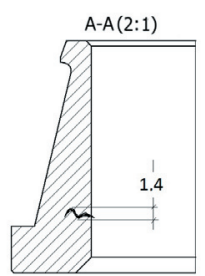

b)

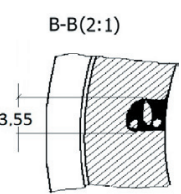

c)
Fig. 6. Cross-sections and a draft of the defect propagation Defect 1, Ring $A$ - dimensions in $\mathrm{mm}$ : a) intersection, b) part section $A$ c) part section $B$

Defect 2, similar to Discontinuity 1 , has the form of a crack or a flattened cavity. It is smaller than Defect 1, and its shape is more irregular (Fig. 8).

Fig. 9 depicts the radiographs for Ring A with a clearly visible Defect 1 and a tiny, even at greater magnification, Defect 2.

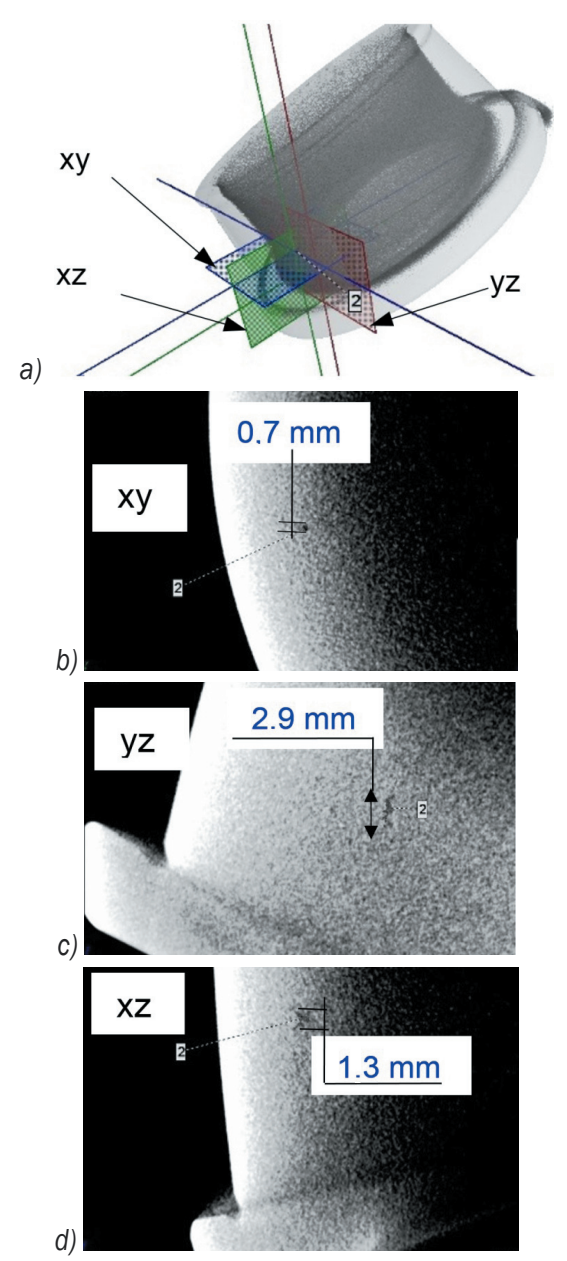

Fig. 7. Selected images of Defect 2 cross-section in planes $X Y, Y Z, X Z$ in reconstruction of Ring $A:$ a) ring $A, b)$ xy intersection, c) $y z$ intersection, d) $x z$ intersection

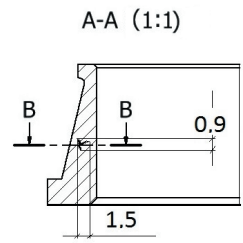

a)

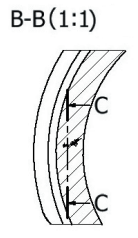

b)

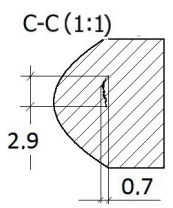

c)
Fig. 8. Cross-sections and a draft of the defect propagation Defect 2, Ring $A$ - dimensions in $\mathrm{mm}$ : a) intersection, $A$ b) part section $B$ c) part section $C$

In the central part of Ring B, a discontinuity of extended structure was observed. The middle of the defect has the form of a cavity in which the propagating discontinuities (crack-like) are rooted (Fig. 10).

The defect is also visible in Fig. 11 presenting the radiograph of Ring B. 


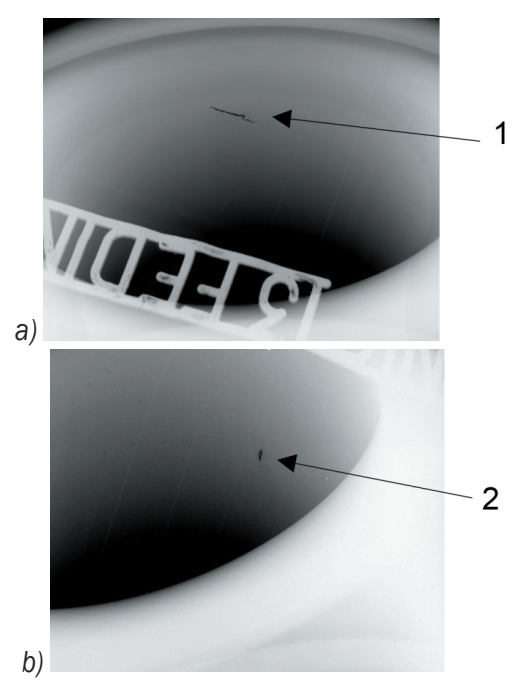

Fig. 9. Radiograph for Ring A: a) defect 1, b) defect 2

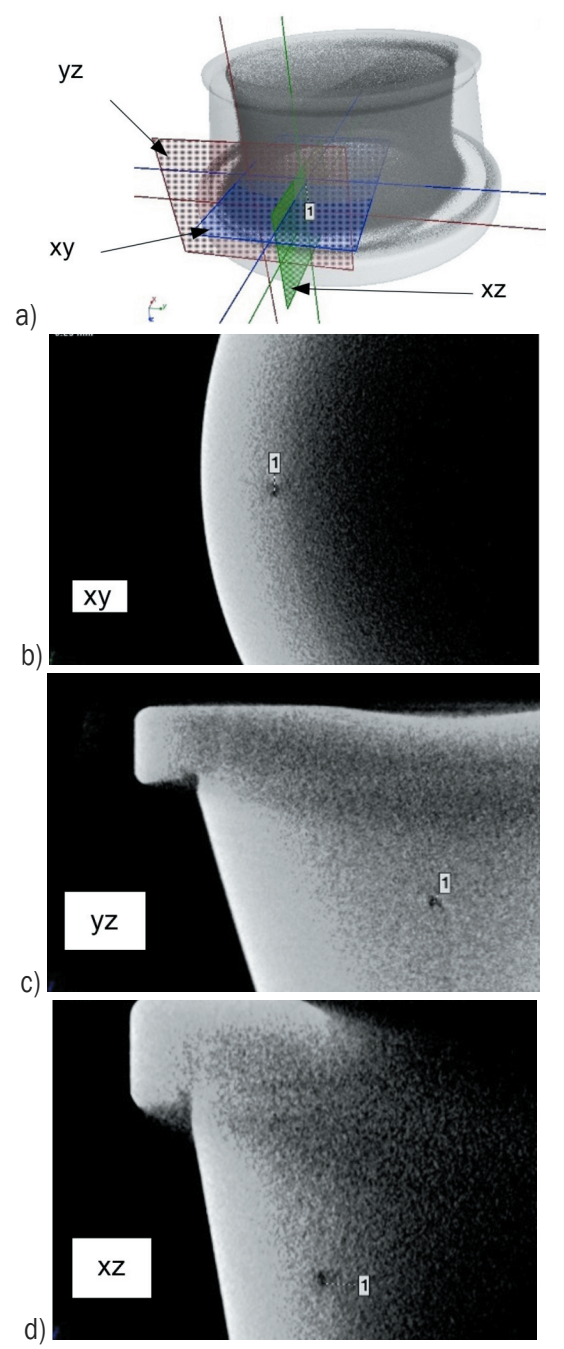

Fig. 10. Selected images of Defect 1 cross-section in planes $X Y$, $Y Z, X Z$ in reconstruction of Ring $B:$ a) ring $B, b)$ xy intersection, c) $y z$ intersection, d) $x z$ intersection

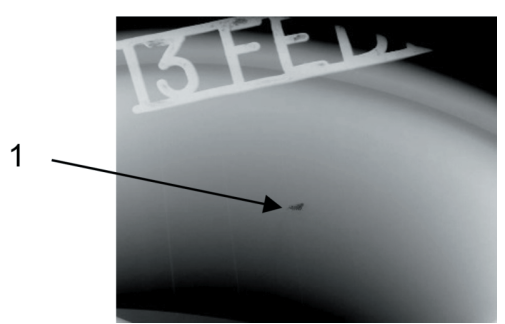

Fig. 11. Radiograph for Ring $B$

\section{CONCLUSIONS}

The computed tomography tests conducted for roller bearing rings with grinding smudges confirmed the existence of structural discontinuities underneath the smudges. These defects become visible after the grinding process but are not visible to the naked eye.

The possibility of multidirectional irradiation, and with it, the multifaceted reconstruction of the tested rings, allows speculations concerning the character, size, shape, and orientation of the defect with reference to the working surfaces in roller bearing rings.

The reconstructions indicate that the discontinuity in Ring A has the form of a crack or cavity. It has an irregular shape oriented perpendicularly to the inner area of the ring. Defect 2, with irregular shapes, also has the form of a crack or a flattened cavity from which the crack propagates towards the inner area of the ring. This defect is smaller and less visible than Defect 1 . The defect located in Ring B has the form of a cavity with discontinuities directed towards the inner area of the ring as well.

Based on the tests conducted, the relation between the grinding defects and subsurface material defects, such as cavities or discontinuities, were determined. These defects are the results of metallurgical processes, and they disqualify the rings from operation.

Since the method is rather time-consuming, it cannot be used in mass production systems for the inspection of the quality of roller bearing rings. However, it is crucial as far as off-line verification of elements qualified as defects is concerned. It can be particularly useful in comparison tests of different defectoscopy techniques applied in mass production.

\section{ACKNOWLEDGEMENT}

This scientific work was executed within the Strategic Programme "Innovative Systems of Technical Support for Sustainable Development of Economy" 
within 2010 to 2014 Innovative Economy Operational Programme.

\section{REFERENCES}

[1] Schillinger, B., Lehmann, E., Vontobel, P. (2000). 3D neutron computed tomography: requirements and applications. Physica B: Condensed Matter, vol. 276278, p. 59-62, DOI:10.1016/S0921-4526(99)01254-5.

[2] Auditore, L., Barna, R.C., Emanuele, U., Loria, D., Trifiro, A., Trimarchi, M. (2008). X-ray tomography system for industrial applications. Nuclear Instruments and Methods in Physics Research B, vol. 266, no. 10, p. 2138-2141, DOI:10.1016/j.nimb.2008.02.082.

[3] Bartscher, M., Hilpert, U., Goebbels, J., Weidemann, G. (2007). Enhancement and proof of accuracy of industrial computed tomography (CT) measurements. Annals of the CIRP - Manufacturing Technology, vol. 56, no. 1, p. 495-498, DOI:10.1016/j.cirp.2007.05.118.

[4] Krimmel, S., Stephan, J., Baumann, J. (2005). 3D computed tomography using a microfocus X-ray source: Analysis of artifact formation in the reconstructed images using simulated as well as experimental projection data. Nuclear Instruments and Methods in Physics Research A: Accelerators, Spectrometers, Detectors and Associated Equipment, vol. 542, no. 1-3, p. 399-407, DOI:10.1016/j.nima.2005.01.171.

[5] Buffiere, J.-Y., Maire, E., Adrien, J., Masse, J.-P., Boller, E. (2010). In situ experiments with $X$ ray tomography: An attractive tool for experimental mechanics. Experimental Mechanics, vol. 50, no. 3, p. 289-305, DOI:10.1007/s11340-010-9333-7.

[6] Salvo, L., Cloetens, P., Maire, E., Zabler, S., Blandin, J.J., Buffière, J.Y., Ludwig, W., Boller, E., Bellet, D., Josserond, C. (2003). X-ray micro-tomography an attractive characterisation technique in materials science. Nuclear Instruments and Methods in Physics Research B: Beam Interactions with Materials and Atoms, vol. 200, p. 273-286, DOI:10.1016/S0168583X(02)01689-0.

[7] Ludwig, W., King, A., Reischig, P., Herbig, M., Lauridsen, E.M., Schmidt, S., Proudhon, H., Forest, S., Cloetens, P., Rolland du Roscoat, S., Buffière, J.Y., Marrow, T.J., Poulsen, H.F. (2009). New opportunities for 3D materials science of polycrystalline materials at the micrometre length scale by combined use of X-ray diffraction and X-ray imaging. Materials Science and Engineering A, vol. 524, no. 1-2, p. 69-76, DOI:10.1016/j.msea.2009.04.009.

[8] Babout, L., Maire, E., Fougères, R. (2004). Damage initiation in model metallic materials: X-ray tomography and modelling. Acta Materialia, vol. 52, no. 8, p. 2475.2487, DOI:10.1016/j.actamat.2004.02.001.

[9] Babout, L., Maire, E., Buffière, J.Y., Fougères, R. (2001). Characterization by x-ray computed tomography of decohesion, porosity growth and coalescence in model metal matrix composites. Acta
Materiala, vol. 49, no. 11, p. 2055-2063, DOI:10.1016/ S1359-6454(01)00104-5.

[10] Maire, E., Babout, L., Buffiere, J.Y., Fougères, R. (2001). Recent results on 3D characterisation of microstructure and damage of metal matrix composites and a metallic foam using X-ray tomography. Materials Science and Engineering A, vol. 319-321, p. 216-219, DOI:10.1016/S0921-5093(01)00924-8.

[11] Kádár, Cs., Maire, E., Borbély, A., Peix, G., Lendvai, J., Rajkovits, Zs. (2004). X-ray tomography and finite element simulation of the indentation behavior of metal foams. Materials Science and Engineering A, vol. 387389, p. 321-325, DOI:10.1016/j.msea.2004.03.091.

[12] Viot, P., Plougonven, E., Bernard, D. (2008). Microtomography on polypropylene foam under dynamic loading: 3D analysis of bead morphology evolution. Composites A: Applied Science and Manufacturing, vol. 39, no. 8, p. 1266-1281, DOI:10.1016/j.compositesa.2007.11.014.

[13] Roux, S., Hild, F., Viot, P., Bernard, D. (2008). Threedimensional image correlation from X-ray computed tomography of solid foam. Composites A: Applied Science and Manufacturing, vol. 39, no. 8, p. 12531265, DOI:10.1016/j.compositesa.2007.11.011.

[14] Stanzick, H., Wichmann, M., Weise, J., Helfen, L., Baumbach, T., Banhart, J. (2002). Process control in aluminium foam production using real-time x-ray radioscopy. Advanced Engineering Materials, vol. 4, no. 10, p. 814-823, DOI:10.1002/1527-2648(20021014)4:10<814::AIDADEM814>3.0.CO;2-5.

[15] Toda, H., Ohgaki, T., Uesugi, K., Kobayashi, M., Kuroda, N., Kobayashi, T., Niinomi, M., Akahori, T., Makii, K., Aruga, Y. (2006). Quantitative assessment of microstructure and its effectson compression behavior of aluminum foams via high-resolution synchrotron X-ray tomography. Metallurgical and Materials Transactions A, vol. 37, no. 4, p. 1211-1219, DOI:10.1007/s11661-006-1072-0.

[16] Lame, O., Bellet, D., Di Michiel, M., Bouvard, D. (2003). In situ microtomography investigation of metal powder compacts during sintering. Nuclear Instruments and Methods in Physics Research B, vol. 200, p. 287294, DOI:10.1016/S0168-583X(02)01690-7.

[17] Kastner, J., Harrer, B., Requena, G., Brunke, O. (2010). A comparative study of high resolution cone beam $\mathrm{X}$-ray tomography and synchrotron tomography applied to Fe-and $\mathrm{Al}$-alloys. NDT\&E International, vol. 43, no. 7, p. 599-605, DOI:10.1016/j.ndteint.2010.06.004.

[18] Kastner, J., Harrer, B., Degischer, H.P. (2011). High resolution cone beam X-ray computed tomography of 3D-microstructures of cast Al-alloys. Materials Characterization, vol. 62 , no. 1, p. 99-107, DOI:10.1016/j.matchar.2010.11.004.

[19] Węglewski, W., Bochenek, K., Basista, M., Schubert, Th., Jehring, U., Litniewski, J., Mackiewicz, S. (2013). Comparative assessment of Young's modulus measurements of metal-ceramic composites using 
mechanical and non-destructive tests and microCT based computational modeling. Computational Materials Science, vol. 77, p. 19-30, DOI:10.1016/j. commatsci.2013.04.007.

[20] Maire, E., Fazekasb, A., Salvob, L., Dendievelb, R., Youssefa, S., Cloetensc, P., Letangd, J.M. (2003). X-ray tomography applied to the characterization of cellular materials. Related finite element modeling problems. Composites Science and Technology, vol. 63, no. 16. p. 2431-2443, DOI:10.1016/S0266-3538(03)00276-8.

[21] Burch, S. (2002). Measurement of density variations in compacted parts using X-ray computerized tomography. Metal Powder Report, vol. 57, no. 2, p. 24-28, DOI:10.1016/S0026-0657(02)85009-3.

[22] Ueta, K., Tani, K., Kato, T. (2000). Computerized $\mathrm{X}$-ray tomography analysis of three-dimensional fault geometries in basement-induced wrench faulting. Engineering Geology, vol. 56, no. 1-2, p. 197-210, DOI:10.1016/S0013-7952(99)00143-X.

[23] Eskisar, T., Otani, J., Hironaka, J. (2012). Visualization of soil arching on reinforced embankment with rigid pile foundation using X-ray CT. Geotextiles and Geomembranes, vol. 32, p. 44-54, DOI:10.1016/j. geotexmem.2011.12.002. 